\title{
Midcult y arte de masas en la sociedad contemporánea
}

\author{
Midcult and mass art in contemporary society
}

\author{
Ma JESÚS GODOY DOMÍNGUEZ
}

\begin{abstract}
Resumen: Como expresión de la clásica dicotomía entre alta cultura y cultura popular, la estética y la teoría del arte han tendido siempre a jerarquizar las artes, distinguiendo entre un arte superior $\mathrm{y}$ otro inferior. Este trabajo pretende demostrar que esa tendencia ha sido reemplazada hoy por otra a la igualación, de acuerdo con el concepto midcult de Dwight MacDonald. Retomamos aquí dicho concepto para explicar la situación del arte actual, pero sin la connotación peyorativa que le dio su autor y asociándolo, en cambio, a un esfuerzo por elevar el nivel artístico y cultural del gran público.

Palabras clave: estética, arte culto, vanguardias, arte de masas, midcult, MacDonald.
\end{abstract}

\begin{abstract}
As an expression of the classical dichotomy between high culture and low culture, aesthetics and art theory have always tended to hierarchize arts, thus distinguishing between high art and low art. This tendency has been replaced nowadays by another one that, instead, tries to equalize, according to the concept of midcult as theorized by Dwight MacDonald. In this article, we take this concept back in order to explain the situation of art today. We don't assume, though, MacDonald's prejudiced approach; on the contrary, we see the idea of parity as an effort to raise the cultural and artistic level of the general public.

Keywords: aesthetics, high art, avant-garde, mass art, midcult, MacDonald.
\end{abstract}

\section{Alta cultura versus cultura de masas; vanguardia versus arte de masas}

Casi como una necesidad imperiosa o un impulso irrefrenable, el pensamiento filosófico ha tendido siempre a separar, distinguir y jerarquizar las $\operatorname{artes}^{1}$, recubriendo de ese modo a unas de gloria -las agrupadas al llegar el siglo XVIII en el moderno sistema de las artes o las bellas artes de toda la vida- y condenando, por el contrario, a otras a la marginación y al desprecio -las artesanías, tradicionalmente excluidas de ese sistema-, cuando no al olvido -como ha ocurrido, en general, con las artes nacidas a partir del XVIII, momento de

Fecha de recepción: 12/05/2015. Fecha de aceptación: 07/09/2015.

* Profesora contratada doctora del Departamento de Estética e Historia de la Filosofía de la Universidad de Sevi1la (e-mail: godoydom@us.es). Líneas de investigación: estética y teoría de las artes, estética y arte de género, estética contemporánea, estética y medios de comunicación. Publicaciones recientes: "En torno a las artes del espectáculo vivo: una lectura desde la estética", Estudios Filosóficos, vol. 63, nº 183, 2014, pp. 281-298. "Estética y apropiacionismo postmoderno. El caso de María Cañas”. En Molina, A. y Peinado, C. (eds.), Tendencias estéticas y literarias en la cultura contemporánea, Sevilla, Renacimiento, 2014, pp. 225-56.

1 Decimos "siempre" porque desde la antigua Grecia, las artes estaban escindidas ya, como se sabe, en artes vulgares o serviles y artes liberales o nobles. 
la "gran división" como lo llama Larry Shiner $^{2}$, y que, salvo contadas excepciones como el cine o la fotografía, siguen pendientes de ser devueltas a la memoria y de alcanzar algún día visibilidad, caso del diseño o la actividad publicitaria ${ }^{3}$. Dicha tendencia ha formado parte, a su vez, de otra a mayor escala, a segmentar y dividir los bienes culturales en sentido amplio ${ }^{4}$, diferenciando así entre una cultura aristocrática y superior, al alcance sólo de unos cuantos en virtud de su elevada procedencia social y refinada educación, e identificada por eso con la verdadera cultura, y otra cultura de tipo inferior y plebeyo, que adaptándose a la escasa formación y supuesta naturaleza emotiva de la gran mayoría a la que va destinada, es asimilada a la anticultura.

Pero la polarización entre alta cultura y cultura popular adquiriría nuevo sentido con el advenimiento de la sociedad de masas, donde la alta cultura acabaría midiéndose con la también denominada cultura de masas. Ésta aparejaría una forma propia de arte, la del arte masivo, fruto de la nueva sociedad industrial y su perfil específicamente tecnológico -sobre todo, desde finales del siglo XIX y principios del XX, siguiendo a Noël Carroll5- que es lo que ha hecho posible su llegada a las cantidades ingentes de población características de nuestro tiempo. Es por eso que cultura popular y cultura de masas son dos fenómenos distintos -con formas artísticas consiguientemente propias- en la medida en que responden también a dos realidades históricas diferentes: la primera, conocida asimismo como folclore, es la expresión autóctona de una sociedad campesina o pre-moderna, que operando desde abajo, hace emerger ese producto espontáneo del espíritu alejado por lo general de los modos culturales de la nobleza, o de la alta cultura sin más, al igual que lo está, en este sistema de organización social, la gente normal y corriente respecto de la Corte; la segunda, por su parte, es una cultura que en su carácter esencialmente urbano y, por lo tanto, moderno permea al conjunto de la sociedad, pues habiendo en ésta -al menos teóricamente- igualdad entre todos sus miembros, no conoce fronteras ni compartimentos estancos, y viene impuesta además desde arriba por los hombres de negocio en su deseo de controlar e influir en el grueso de la población ${ }^{6}$.

Reciente es, pues, el contraste entre alta cultura y cultura de masas, y recientes son también las respectivas manifestaciones artísticas donde se expresa; de ahí que en nuestros días -o hasta mediados del siglo XX, como veremos después-, el ordenamiento de las artes haya dejado de establecerse, no ya a partir de la antigua escisión entre artes vulgares, mecánicas o serviles y artes liberales, como en la era del arte antes del arte, que diría Hans Belting ${ }^{7}$, sino incluso de la división que implantaría posteriormente el moderno sistema de las artes entre bellas artes y artesanías. En su lugar, la alta cultura ha adoptado como seña de identidad artística a las vanguardias, que por propia idiosincrasia dejaron sin validez todas aquellas

2 La invención del arte. Una historia cultural, Barcelona, Paidós, 2004.

3 Haciéndose eco de esta omisión, Schaeffer ha arremetido contra la estética moderna como responsable, a su juicio, de nuestro estrecho concepto de arte y el alejamiento consiguiente de las experiencias estéticas productivas y receptivas reales. Schaeffer, J.-M., Adiós a la estética, Madrid, Antonio Machado Libros, 2005.

4 Según Umberto Eco en su estudio, ya clásico, Apocalípticos e integrados, Barcelona, Lumen, 2009.

5 Carroll, N., Una filosofía del arte de masas, Madrid, Antonio Machado Libros, 2002, p. 18.

6 Pardo, J. L., Esto no es música. Introducción al malestar en la cultura de masas, Barcelona, Círculo de Lectores/Galaxia Gutenberg, 2007.

7 Imagen y culto: una historia de la imagen anterior a la edad del arte, Madrid, Akal, 2009. 
taxonomías, pero sin que ello supusiera menoscabo alguno para su valor o calidad ${ }^{8}$; por su parte, la cultura de masas ha tomado cuerpo en un arte de consumo generalista, coetáneo al anterior y, en ese sentido, arte asimismo de reciente creación. El afán jerarquizante de la estética filosófica y la teoría del arte ha venido a concretarse así en la antítesis primordial entre movimientos como el cubismo, el neoplasticismo o el suprematismo, por una lado, y prácticas artísticas como el cómic, el videoclip o los dibujos animados, por otro; los primeros, como es fácil suponer, arte en sentido estricto, o mejor, summum del arte, pues por encima de ellos ya no habría nada, y los segundos, pseudoarte, arte de escasa entidad o directamente no-arte por estar pensados para una vasta recepción y ser de fácil accesibilidad, algo que vendrían a solucionar precisamente las vanguardias con su dificultad intrínseca y su público de exquisita formación.

Y hablar de la dicotomía entre vanguardias y arte de masas, exige referirse, siquiera sucintamente, a su máximo promotor, Clement Greenberg, el crítico de mayor influencia en el ámbito artístico del siglo $\mathrm{XX}^{9}$. Fue Greenberg, en efecto, quien enunció los postulados teóricos del menosprecio del que ha venido siendo objeto el arte de masas de manera casi ininterrumpida. Pero el motivo no fue el enorme consumo, como pudiera suponerse en un primer momento; la masificación fue más bien la consecuencia de su renuncia a acogerse a la complejidad y opacidad formal a las que fueron sometiéndose gradualmente las vanguardias hasta desembocar en el expresionismo abstracto, el no va más del arte para Greenberg por su calidad estética suprema y, de ese modo, el único arte realmente de la sociedad contemporánea ${ }^{10}$. Contraviniendo entonces esa búsqueda de la abstracción y entregándose, en cambio, a una recepción cómoda, sencilla y, sobre todo, concurrida al aferrarse a los parámetros figurativos tradicionales, el arte de masas fue rebajado a la condición de arte fraudulento y engañoso, o simplemente a kitsch, según el término empleado por el propio Greenberg con fines claramente degradantes.

\section{Un nuevo paradigma de las artes: la Midcult}

Ahora bien, lo que aquí pretendemos defender es que ese juego de oposiciones y subordinación consiguiente de unas artes a otras, en tanto paradigma artístico tradicionalmente asumido y aceptado, no funciona realmente ya en nuestros días $-\mathrm{o}$ no, al menos, en la manera en la que ha venido haciéndolo-, por más esfuerzos que desde la disciplina estética se han hecho en los últimos tiempos por dignificar el arte de masas e integrarlo de una vez por todas en la categoría artística ${ }^{11}$; acción, dicho sea de paso, que era sin duda necesaria

8 De hecho, si por algo se caracterizaron las vanguardias fue por superar la antigua división entre arte y artesanía, es decir, por desmentir que la ausencia de utilidad fuera una categoría artística y por operar, en general, una desjerarquización a todos los niveles. Ver como ejemplo el catálogo La vanguardia aplicada (1890-1950), Madrid, Fundación Juan March, 2012.

9 A juicio de Arthur Danto en Después del fin del arte. El arte contemporáneo y el linde de la historia, Barcelona, Paidós, 1999, p. 30.

10 En su texto de 1939, "Vanguardia y kitsch". En Greenberg, C., Arte y cultura, Barcelona, Paidós, 2002, p. 29.

11 Junto al libro de Noël Carroll (Una filosofía del arte de masas, op. cit.), al de Larry Shiner (La invención del arte, op. cit.), y los de Jacques Racière y Jean-Marie Schaeffer respectivamente (El reparto de lo sensible. Estética y política, Chile, LOM Ediciones, 2009; Adiós a la estética, op. cit.), son dignos de resaltar también los estudios en nuestro país de Sixto Castro ("Reivindicación estética del arte popular", Revista de Filosofía, 
y que es merecedora por eso de todo respeto y reconocimiento. Entendemos, sin embargo, que se inauguró un nuevo paradigma en el momento en que las vanguardias, relajándose bastante respecto a sus propósitos exclusivistas iniciales y su carácter inasimilable, fueron absorbidas en el sistema social del capitalismo tardío del que tanto habían abominado y al que el arte de masas había pertenecido, en cambio, desde el primer instante en su deseo de alcanzar las mayores cotas de mercado posibles y difundirse a escala prácticamente planetaria. Este proceso de integración, inaugurado hacia mediados del siglo XX y por el que las vanguardias, en un principio desechadas por incomprendidas, acabaron convertidas en un activo social y económico de gran importancia -hasta el punto de formar parte habitualmente de las prácticas publicitarias y mediáticas sin mayores problemas-, tendría como efecto inmediato el acortamiento de la distancia entre un tipo de arte y otro. En la medida en que los dos quedaban a merced del gran público, los dos se ponían también al mismo nivel -por tanto, los dos eran arte o no lo eran, según la perspectiva adoptada- y el clásico sistema de antagonismos dejaba obviamente de funcionar.

Aquella homologación de las artes era reflejo, sin embargo, de un fenómeno más amplio que afectaba al plano cultural en su conjunto. Prueba de ello es que, en el debate sobre la cultura de masas durante los años cincuenta y sesenta, empezó a cobrar fuerza el término "middlebrow", que indicaba justamente eso, el acercamiento de los extremos, no tanto en referencia a los productos culturales propiamente dichos -que tendrían su término específico-, como a la competencia intelectual de sus destinatarios, que parecía estar aumentando exponencialmente: si el individuo "highbrow" era el erudito de siempre y el "lowbrow", el ignorante, el "middlebrow" era alguien que había irrumpido inesperadamente en medio; alguien de abajo como el "lowbrow" pero que a través de un proceso de formación aspiraba a llegar tan arriba como el "highbrow"12. Había surgido, en resumidas cuentas, un nuevo segmento poblacional, que rompiendo los esquemas y estructuras sociales conocidas, apuntaba hacia una igualación, tarde o temprano, de la sociedad. El motor de cambio era la paulatina generalización de la educación superior entre los habitantes de los países occidentales, a partir sobre todo de los años sesenta y, a la vista de los resultados, no hay duda de que se estaba logrando: una cada vez más nutrida clase media, la "middlebrow", accedía a la universidad y adquiría así la preparación que le había valido siglo tras siglo a la clase alta, a la "highbrow", una posición de privilegio frente a la cultura -como frente a la política, las finanzas, el derecho y todo en general-13.

La aparición del "middlebrow" en escena y, junto a él, la posibilidad de tránsito entre niveles sociales se dejó sentir rápidamente en la esfera cultural, donde la línea de demarcación entre alta cultura y cultura de masas fue volviéndose también más difusa y amenazaba con desaparecer -como ha terminado ocurriendo de hecho en la actualidad-. Una de las primeras reflexiones y más estimulantes al respecto, en la que basaremos por eso nuestra

vol. 27, n 2, 2002, pp. 431-451), Rosa Fernández ("La estética invisible del arte popular", Suplementos de Contrastes. Revista Internacional de Filosofía, n ${ }^{\circ} 13,2008$, pp. 41-54) y Fernando Infante ("Las tres estéticas y el límite", Estudios Filosóficos, vol. 64, n 185, 2015, pp. 35-48), entre otros.

12 Ver Busquet, J., Lo sublime y lo vulgar. La “cultura de masas” o la pervivencia de un mito, Barcelona, Editorial UOC, 2008, pp. 92-93.

13 Una curiosa explicación de este fenómeno, a partir de la portada del Sgt. Pepper's de los Beatles, puede leerse en Pardo, Esto no es música, op. cit., pp. 10-16. 
argumentación de ahora en adelante, es la de Dwight MacDonald ${ }^{14}$, cuyos planteamientos creemos que es hoy en día cuando tienen verdadera vigencia -con independencia de que sirvieran para explicar entonces lo que empezaba a suceder ya tímidamente-, aunque desprovistos de toda la pátina negativa con la que el autor los recubrió y los dio a conocer a sus coetáneos ${ }^{15}$. De esta propuesta, nos interesa sobre todo que, frente a los dos niveles culturales heredados de la tradición, establecía tres, en consonancia con la nueva división igualmente tripartita de la sociedad. Así, junto a la cultura elitista, representada para el autor, todavía entonces, por los ejemplos más soberbios de las vanguardias -citaba concretamente a Picasso, James Joyce y Stravinsky- y a una cultura más común, a la que ni siquiera consideraba dentro de los parámetros culturales y llamaba por eso masscult -aquí mencionaba el rock and roll, las portadas del Saturday Evening Post a cargo del ilustrador Norman Rockwell y toda la oferta televisiva made in Hollywood-, contemplaba una tercera categoría que, figurando entre las anteriores, deshacía por completo la organización de la cultura hasta entonces: la midcult, a la que dedicaremos el resto de nuestro estudio.

La midcult era y es la cultura media surgida del encuentro entre la alta y baja cultura o cultura de masas. Lo lógico sería entender este encuentro como resultado del proceso de aproximación iniciado tanto desde arriba como desde abajo hacia el extremo contrario, fruto del cual se generaría un intrincado mecanismo de préstamos y trasvases por igual de un lado a otro -que es lo que aplicaremos aquí al arte de nuestro tiempo-. Sin embargo, MacDonald sólo tuvo en cuenta una de esas dos posibilidades, dedicando por entero su ensayo al acercamiento promovido desde abajo, por asimilación quizás con el sujeto "middlebrow", que nunca era un "highbrow", sino un "lowbrow" con ínfulas de "highbrow" y, pese a ello, su visión del fenómeno fue absolutamente negativa y pesimista. Es decir, pudiendo entender que la midcult mejoraba la cultura al tirar de ella en un movimiento ascendente, al igual que el individuo "middlebrow", de orígenes humildes, escalaba puestos en la sociedad gracias a su preparación, pensaba, por el contrario, que la empeoraba. En la medida en que ascendía desde abajo, sólo era cultura de masas haciéndose pasar por alta cultura, o la misma anticultura arrebatándole sus hallazgos a la cultura para aparentar una excelencia que en ningún caso tenía. En ella, se mezclaba entonces "lo mejor" de la cultura de arriba, a saber, su capacidad de romper con la tradición e innovar -recordemos que el autor seguía pensando en las vanguardias como referente artístico-, con "lo peor" de la de abajo, que era su difusión a gran escala e inserción en nuevos contextos donde adquirir nuevas funciones. Por eso, la midcult era para MacDonald "lo peor de lo peor"; en su escala jerárquica, iba por detrás incluso de la cultura de masas -que ya era decir-, blanco común de las críticas entre los de su generación. Él compartía desde luego esa infravaloración ${ }^{16}$, pero creía también que en ella nadie se llamaba a engaño: siendo sus productos fácilmente identificables

14 En su texto de 1962, "Masscult and Midcult" (ver en MacDonald, D., Masscult and Midcult. Essays against the American grain, Nueva York, The New York Review of Books, 2011).

15 Aunque entendiendo que existen evidentes puntos en común entre los planteamientos de MacDonald y los de la Escuela de Frankfurt en el rechazo ideológico a la cultura de masas, creemos también que la postura extremadamente rica, compleja y llena de matices de Adorno y Horkheimer entre otros, exige un estudio en sí mismo que excede las pretensiones de este trabajo, por lo que nos centraremos en el caso específico del crítico norteamericano.

16 No en vano, la calificó de "pesadilla cultural” y de "Kulturkatzenjammer". Ibid, p. 31. 
$\mathrm{y}$, en ese sentido, transparentes, quien optaba por consumirlos sabía en todo momento lo que tenía entre manos, algo de ínfimo nivel y nulo valor estético. En cambio, los productos de la midcult inducían perversamente a la confusión: hacían creer al público que estaba consumiendo algo valioso, o que estaba teniendo contacto con la cultura, cuando no era así, de ahí su opacidad y falsedad intrínsecas, y de ahí también que el autor se mostrara especialmente incisivo con ella ${ }^{17}$.

Pero lo realmente pernicioso de la midcult era su fatal influencia sobre la cultura refinada, a la que degradaba y corrompía. Al tomar prestados sus formas, sus elementos y giros estilísticos para parecerse todo lo posible a ella y querer darles al mismo tiempo gran difusión, estaba obligada, decía MacDonald, a volverlos accesibles y disfrutables a un público, que si bien no era el de inteligencia inferior de la cultura de masas porque tenía formación académica, sí era notablemente más amplio que aquél para el que en principio fueron pensados, violentando así su dificultad extrema, su hermetismo en una palabra, junto a su carácter minoritario. Lejos de contribuir entonces a elevar el nivel cultural de la población, lo único que se lograba con esa apropiación era un irremediable descenso de lo normalmente situado en las cimas culturales. El panorama era aún peor teniendo en cuenta que, para competir con esa forma de cultura media cada vez más extendida, para sobrevivir en suma en aquel medio hostil, los creadores de alta cultura, los artistas "serios", tendrían además que adaptar sus obras y su lenguaje a ese nivel engrosado de recepción -las propias vanguardias lo habían hecho ya por aquellas fechas al integrarse en el sistema económico y artístico institucional que ellas mismas habían rechazado-, apuntando de nuevo así hacia abajo en lugar de hacia arriba y abocando finalmente a la ruina cultural. Concluía de todo ello MacDonald: la cultura aurática y solvente de otro tiempo iba a ser reemplazada inexorablemente por aquella otra sin aura, sin rédito y mediocre de la midcult; habiendo llegado para quedarse, amenazaba con imponerse tarde o temprano en el terreno artístico y cultural ${ }^{18}$.

En efecto, MacDonald acertó de lleno al afirmar que la pureza de los extremos era cosa del pasado y que el presente -y sobre todo el futuro- se escribía en términos de contaminación. Erró, por el contrario, su diagnóstico en cuanto a que esa contaminación tendría necesariamente un efecto devastador sobre el arte y la cultura, como pensaba la mayoría en su tiempo. El motivo es que la contaminación ofrecía un abanico de posibilidades, prácticamente infinitas, todas ellas por descubrir y por explorar, con las que los creadores de aquella época -no digamos ya los de ésta- empezaban a trabajar, muchas de las cuales serían realmente valiosas y aprovechables, según han demostrado prácticas artísticas posteriores como las que analizaremos después. Pero para tomar conciencia de ello, era preciso despojarse antes de los prejuicios hacia la idea de hibridación, viniera ésta de donde viniera, de abajo, en la que MacDonald reparó especialmente con vistas a rechazarla, o de arriba, a la que aludió sólo de pasada, como efecto colateral de aquélla. Si hubiera entrado a fondo en este otro supuesto, tal vez se hubiera percatado de que buena parte de las conquistas de las vanguardias que él tanto admiraba como exponentes de alta cultura, se relacionaban

17 Llegando a tildarla de "hija bastarda" de la masscult. Ibid, p. 25.

18 "El peligro es que los valores de la midcult, en lugar de ser transitorios -como "precio del progreso"-, parece que van a convertirse en una envilecedora norma permanente". Ibid., p. 52. Traducción de la autora. 
estrechamente con su incursión en la cultura de masas ${ }^{19}$, contribuyendo activamente así a la formación de la midcult que en nada las desmerecían. Hubiera caído en la cuenta también de que en el mundo del arte culto simultáneo estaba emergiendo un movimiento, el pop, que por aquellas fechas había deslumbrado ya a otro influyente crítico de arte como era Arthur Danto $^{20}$, y que adquiría carta de ciudadanía llevando precisamente al plano compositivo los objetos y personajes de la cultura subalterna, lo que no estaba reñido, sin embargo, con su capacidad de hacer reflexionar sobre el carácter mítico de esos nuevos actores sociales, sobre el tributo que frecuentemente les rendimos pese a su carácter irreal y evanescente, luego haciendo alarde nuevamente de una combinación consustancial a la midcult.

De haber sido más ecuánime, MacDonald podría haber descubierto todo eso del viaje emprendido por lo de arriba hacia abajo, que prácticamente pasó inadvertido ante sus ojos. Pero habría descubierto más, esta vez de lo de abajo viajando hacia arriba, que no era tan catastrófico, ni mucho menos, como él decía. Por poner un ejemplo: que Cecil Beaton empleara como fondo de sus fotografías de moda, para la revista Vogue, el Mural que Peggy Guggenheim encargó a Pollock para su nuevo apartamento ${ }^{21}$, no tenía que suponer forzosamente la banalización de dicha obra; Pollock ni más ni menos, el grande entre los grandes dentro de las vanguardias en tanto expresionista abstracto $^{22}$. No era desnaturalizar su esencia ni nada por el estilo, entre otras razones, porque la pintura en cuestión, lejos de los propósitos grandilocuentes que la crítica de arte norteamericana proyectó en un arte rupturista y transgresor formalmente como éste, había sido concebida en verdad para algo tan corriente y poco selecto como posar delante; algo con lo que el artista estuvo de acuerdo además desde el primer instante por la oportunidad única que con ello le brindaba su patrona de darse a conocer y de enrolarse en los circuitos artísticos de entonces. No fue tampoco una excepción ni algo puntual, pues algunas de las piezas más afamadas del pintor tuvieron el mismo fin: apenas estuvieron secas, servieron de fondo para las modelos que poblaban las páginas de las revistas de moda de la época. En el caso de Pollock, se daba además la circunstancia de que parte de su éxito tuvo que ver con la valoración positiva que hizo de su obra otra revista de difusión general -y no tanto de crítica especializada, que también las hubo, pero cuyo alcance era lógicamente más restringido-, otro órgano de la cultura de masas como era Life a fines de los años cuarenta.

Resumiendo, que ni lo de arriba estaba tan alto ni era tan puro como se pensaba, ni lo de abajo era tan profundo ni corrosivo. Tendiendo a confluir, cada vez más, en el espacio intermedio de la midcult, aquello que desde el principio tenía valor artístico o cultural lo conservaba, cualquiera que fuera su origen, y lo que carecía de él no por ello lo ganaba. No era, por tanto, un problema de fraude o de estafa lo que aquí había, como aseguraba Mac-

19 El muestrario es bastante amplio: el ingenio cubista del collage, a partir de recortes de periódicos o anuncios publicitarios, a los que acabaron sumándose elementos de toda índole (chinchetas, hojas de árboles, paños de croché...); el fotomontaje dadaísta o constructivista, gracias a las imágenes de revistas y de los medios de comunicación en general de la época; o los mismos artistas como Sonia Delaunay, Kurt Schwitters o René Magritte, que simultanearon la faceta propiamente artística con la publicitaria en su tarea profesional como creadores.

20 Danto, Después del fin del arte, op. cit., p. 147.

21 Crown, Th., El arte moderno en la cultura de lo cotidiano, Madrid, Akal, 2002, pp. 44-55.

22 Para Greenberg, en primer lugar, e influido por él como de hecho lo estaba, cabe suponer que también para MacDonald. 
Donald, sino de resistencia a los cruces y a las permutas, a la posibilidad de que el elitismo cultural pudiera perder su hegemonía y al que nuestro autor, como otros muchos, seguían aferrándose pese a su carácter evidentemente anacrónico. Todo se reducía, pues, a superar esa resistencia para poder advertir las muchas ventajas que el nuevo espacio cultural aparejaba, sobre todo en el capítulo correspondiente a expresiones artísticas con las que nadie contaba por insospechadas; expresiones surgidas de los cambios a los que eran sometidos ciertos elementos, ciertas formas y esquemas, al extraerlos de su contexto original e introducirlos en otro distinto para darles nuevo significado y nueva función; algo, por cierto, en lo que el arte culto de las vanguardias era ya un veterano. Pues si algo empezaba a quedar claro por entonces es que, traspasando las fronteras del propio territorio, las formas artísticas, elevadas o populares, no permanecían inalteradas; resultaban, en cambio, tan profundamente transformadas que daban lugar a un nuevo producto, de ahí el enriquecimiento y la ampliación cultural, a la inversa de lo que siempre quiso ver en ello MacDonald.

\section{Un ejemplo paradigmático: el cine y sus derivados}

Pensar que el rebasamiento de fronteras causaría por fuerza un grave perjuicio a la cultura honorable, como hacía MacDonald, era cerrar los ojos a la evidencia; una evidencia que además no era nueva por cuanto había aflorado con el cine, del que, pese a su naturaleza masiva, nadie discutía ya, por aquellas fechas, su condición artística. Pero no siempre fue así, como se sabe, porque en sus inicios fue considerado un simple espectáculo de barraca de feria a años luz de las bellas artes, del arte a fin de cuentas. Gracias a la labor desplegada, sin embargo, por filósofos del arte y pensadores como Walter Benjamin, acabó ingresando en ese distinguido grupo. Pero para llegar hasta ahí fue necesario que dos artes consagradas como el teatro y la literatura se bajaran antes de su pedestal y le prestaran ayuda. Ciertamente, esas artes especialmente doctas y de amplio recorrido histórico - de la primera, hablaron ampliamente ya Platón y Aristóteles y de la segunda, hay que recordar cómo formó parte de aquel proto-agrupamiento artístico que fue el lema horaciano ut pictura poesis en el periodo helenístico- cedieron gustosamente al cine algunos de sus elementos característicos y no por ello se malograron. Es decir, que cuando el drama y la novela decimonónica -la ficción breve también, aunque en menor medida- exportaron sus estructuras narrativas a la naciente industria cinematográfica y las pusieron en manos de cineastas como Griffith, John Ford o Howard Hawks en el paso del cine primitivo al cine clásico ${ }^{23}$, no se produjo ninguna "adulteración" de dichas artes, que diría MacDonald. El teatro, la novela y el relato corto siguieron siendo tan sólidos y diferenciados como lo habían sido antes de esa concesión y así los hemos conocido en nuestros días.

$\mathrm{Y}$, sin embargo, la suma de todos aquellos elementos hizo posible el surgimiento de un nuevo arte por ampliación y desarrollo de los existentes; un arte con todas las de la ley -aunque al principio no se viera así-, en la medida en que los recursos y fórmulas de los que inicialmente se había nutrido adquirían en él nueva plasmación, fruto también de la nueva especificidad artística, que a la hora, por ejemplo, de construir una historia coherente

23 Thompson, K., "De primitivo a clásico", en: D. Bordwell, J. Staiger y K. Thompson: El cine clásico de Hollywood. Estilo cinematográfico y modo de producción hasta 1960, Barcelona, Paidós, 1997, pp. 171-190. 
y unitaria, obligaba a adaptar el acostumbrado esquema aristotélico de planteamiento, nudo y desenlace a requisitos puramente fílmicos como la visualización de los hechos -pues el nuevo arte era eminentemente visual- o la condensación temporal de la trama -porque, pensado para el entretenimiento, su consumo no debía exceder el de una velada amena-. Los teóricos e historiadores del cine han insistido siempre en ello, en que el clasicismo cinematográfico alcanzado en los años treinta del siglo XX, aunque tradicional, fue al mismo tiempo único ${ }^{24}$. Pero nada comparado con el mayor condicionante del nuevo arte, la necesidad de llegar a grandes cantidades de población, que apremiaba a clarificar todo lo posible la historia a fin de hacerla lo más ampliamente comprensible y evitar que el público se perdiera en ella; a depurarla, en suma, de todo lo superfluo -que en la novela realista y naturalista del XIX era mucho, debido a sus profusas descripciones de personajes y ambientes- y a concentrar la trama en lo verdaderamente importante. Con ello, el cine contribuyó a divulgar entre el gran público los modelos narrativos habituales de la minoría burguesa y, al hacerlo, se volvió una de las primeras expresiones artísticas de la midcult, de la que pronto se escindiría, no obstante, una variante culta o de autor, destinada otra vez a satisfacer las necesidades diferenciadoras de un pequeño segmento poblacional, frente a la variante más comercial o de consumo mayoritario.

El ejemplo del cine nos interesa particularmente pues, habiéndose constituido como arte autónomo a partir de otras artes, y sin repercutir negativamente en ellas sino todo lo contrario, contribuyendo a ampliar el horizonte cultural, él mismo ha dado pie, a su vez, a la configuración de nuevas formas artísticas y culturales que se extienden hasta nuestros días; formas midcult que tampoco han causado ningún daño en el arte del que han emanado. La primera que vamos a abordar nos remite al cineasta Alfred Hitchcock, quien por las mismas fechas aproximadamente en que MacDonald dirigía sus invectivas contra los productos del nivel cultural intermedio, se embarcaba en un proyecto que pondría de relieve una vez más que la delimitación entre las artes era de otro tiempo, siendo lo propio del nuevo la reunión y la confluencia. Ese proyecto era la teleserie, un subproducto cinematográfico de reciente creación, pensado para un medio en pleno auge en la época como la televisión -en igual medida, denostado en tanto emblema de la cultura de baja calidad que según sus detractores se estaba entonces imponiendo-, donde los principios narrativos del cine clásico, del arte a fin de cuentas, eran sometidos a un proceso de simplificación y reformulación, junto a influencias no artísticas como la de la publicidad -que no era arte entonces, como sigue sin serlo ahora-, para llegar a un público numeroso como el televisivo y permitir a los grandes estudios hollywoodienses salir a flote de la profunda crisis económica en la que estaban sumidos desde finales de la década precedente ${ }^{25}$. El resultado sería una fórmula discursiva nueva que, aunque inspirada originariamente en el modelo cinematográfico establecido -el denominado Modo Representativo Institucional (M.R.I.) o "modelo Hollywood"26-, y vulgarizando con ello sus formas, le iba a servir, paradójicamente, a Hitchcock para apuntalar dicho modelo y abrir las puertas de par en par a la modernidad fílmica.

24 Ibid., p. 188.

25 Castro de Paz J. L., El surgimiento del telefilme. Los años cincuenta y la crisis de Hollywood: Alfred Hitchcock y la televisión, Barcelona, Paidós, 1999, pp. 21-29.

26 Denominación de Noël Burch (El tragaluz del infinito, Madrid, Cátedra, 1987). 
Pero desde la estrechez de miras de MacDonald, el caso de Hitchcock no podía ser sino el de un maestro del séptimo arte claudicando por fuerza mayor, esto es, por la imposibilidad de competir con los productos de masas. En cambio, para nosotros es otro testimonio más de que las fronteras entre las artes se estaban desdibujando y de que los artistas, dejando atrás prestigio y credibilidad, iban a rentabilizar esa situación, haciendo coincidir en el mismo plano lo de arriba, que ya no era tan "bueno", con lo de abajo, que tampoco era tan "malo", para ver qué ocurría. Y lo que ocurrió fue lo siguiente: que desde arriba, el arte del cine suministró el soporte narrativo básico del nuevo producto audiovisual -del nuevo arte en definitiva, aunque ni por asomo fue considerado como tal entonces, como tampoco lo es ahora-, en el que luego se introdujeron importantes y decisivas modificaciones para hacerse independiente, como el acortamiento de la historia -ya de por sí corta, según sabemos, respecto a las obras dramáticas y novelísticas-, un ritmo vertiginoso -propio de los tiempos que corrían y del medio en que se insertaba-, el giro fuertemente sorpresivo del final o toque Hitckcock, la ruptura de la ilusión de realidad mediante los monólogos del director previos y posteriores al relato y, sobre todo, la introducción de pausas publicitarias impidiendo el desarrollo de corrido de éste; desde abajo, ocurrió, por su parte, que el no-arte de la teleserie dejó igualmente su impronta en la filmografía posterior del director, de manera que el carácter experimental y moderno, las virtudes excepcionales señaladas por la crítica en películas como Psicosis, están estrechamente ligadas a esta influencia, que se dejaba sentir, entre otros aspectos, en el sorpresivo final -con el que atrapar mejor al espectador-, en las escasas localizaciones exteriores -por el reducido presupuesto-, el predominio de los planos cortos y cercanos - por su adaptación a la pequeña pantalla- y el escueto número de personajes - por la necesidad de simplificar la trama-27.

Quiere decirse que ante un intercambio entre la cultura del más alto nivel y la de nivel más modesto como el que entrañaron las teleseries de Hitchcock, no cabía hablar ni de descuido o negligencia por parte de la primera, ni de injerencia o intromisión por parte de la segunda, como podía pensarse desde el enfoque miope de MacDonald. No cabía, por la sencilla razón de que el Hitchcock más intelectual, el highcult, creador de un universo cinematográfico de autor que le valdría el título de primer cineasta moderno, incluso estar emparentado con el mismísimo Shakespeare ${ }^{28}$, había crecido codo con codo con el Hitchcock más comercial y masscult, con el showman televisivo postergado durante mucho tiempo -demasiado e injustamente, como se ha visto después- para no mancillar el nombre del primero ${ }^{29}$. El Hitchcock intelectual alimentó así al Hitchcock comercial a la vez que se alimentaba de él, creándose así entre ellos una tupida red de relaciones y entrecruzamientos

27 Castro de Paz, El surgimiento del telefilme, op. cit., p. 178.

28 Según la interpretación del reconocido teórico Robin Wood sobre la película Psicosis. Ver en Bordwell, D., El significado del filme, Barcelona, Paidós, 1995, pp. 251-255.

29 El Hitchcock highcult es el que admiraban los cineastas y cinéfilos principalmente europeos, como certifica el propio Truffaut, quien en la introducción de El cine según Hitchcock, fruto de su larga entrevista mantenida con el director de cine británico, afirma sin paliativos: “(...) si contemplamos el panorama de Hollywood en 1966, Howard Hawks, John Ford y Alfred Hitchcock se nos aparecen como los únicos herederos de los secretos de Griffith" (Truffaut, F., El cine según Hitchcock, Madrid, Alianza, 2003, p. 21). Sin embargo, el hecho de que en esa entrevista se soslaye prácticamente toda referencia a la amplia y popular producción televisiva del director, al Hitchcock más masscult, ha llevado a pensar que su admiración dejaba de lado este aspecto del hacer creativo del británico (ver Castro de Paz, El surgimiento del telefilme, op. cit., nota 8, p. 75). 
muy a lo midcult de la que ambos perfiles del director salieron beneficiados: el highcult, porque alcanzó un índice de popularidad y una difusión de su lenguaje, su estilo y su manera de hacer cine jamás imaginados ${ }^{30}$, al tiempo que se dotó de los instrumentos con los que ir más allá del clasicismo cinematográfico; y el masscult, porque consiguió revestir el producto cultural televisivo de la reputación y el aura, al fin y al cabo, de los mejores productos hollywoodienses.

Pero si alguien salió realmente ganando con estas transferencias fueron sin duda los espectadores, por mucho que MacDonald se empeñase en lo contrario. Porque sobre expresiones artísticas y culturales consagradas, sobre convenciones narrativas aceptadas en el campo cinematográfico, se les fue presentando propuestas cada vez más complejas y elaboradas que redundaron en una madurez receptiva progresiva; sobre todo desde el momento en que la oferta de productos midcult nacidos del cine fue aumentando y diversificándose. A la teleserie, siguió, en ese sentido, el videoclip en los años ochenta, que supuso un paso más en ese proceso de elevación cultural, puesto que los códigos narrativos que vertebraron su estructura no fueron tanto los del cine clásico, como los de vanguardia, en combinación además con las prácticas de innovación lingüística audiovisual puesta en marcha por el videoarte en los sesenta ${ }^{31}$; recursos importados todos ellos, pues, de la cultura con clase y el arte venerable. Ello explica el carácter frecuentemente fragmentario o discontinuo de su discurso, con el incremento consiguiente del nivel de dificultad -de ahí el esfuerzo de mejora cultural que hay implícito en él-, hasta el punto de que algunos teóricos han preferido hablar más bien de naturaleza antinarrativa ${ }^{32}$. Explica también que la historia que relata, conforme en todo momento con la canción a la que acompaña, sea más sugerida que abiertamente revelada, como forma de atrapar y comprometer al espectador en su reconstrucción; de darle, en definitiva, mayor cota de participación y exigirle un trabajo intelectual ausente en otro tipo de productos.

Pero ni por esas el videoclip ha alcanzado el crédito suficiente para ingresar en la cultura de los connaisseurs, de manera que sigue a las puertas del territorio artístico esperando a que un día se abran para él. El principal escollo aquí, aparte, por supuesto, del destinatario masivo, es la estrecha relación mantenida con la publicidad -que ya hemos dicho que está lejos de ser entendida como arte-, pues en el videoclip no es que haya interrupción de la continuidad narrativa para introducir un elemento publicitario que le es completamente ajeno, como ocurría en la teleserie; es que él es en sí mismo un soporte publicitario de la industria discográfica. De todos modos, esa función comercial es tan sutil que pasa inadvertida frente a la importancia que cobra un aspecto puramente artístico como el de la forma. Luego el videoclip nunca apela directamente a la compra del producto, como hace, en cambio, el spot publicitario normal, encargándose sólo de difundirlo; de ahí que su distancia respecto al

30 A lo que ayudó, sin duda, la Hitchcock Baker Productions Limited, una pequeña productora fundada por el propio Hitchcock para generar noticias constantes sobre su propia vida y proyectos (De Felipe, F., "La sombra de una de(u)da: publicitarios y cineastas", Trípodos, n 18, 2006, pp. 95-108).

31 Sedeño Valdellós, A. M., "El videoclip musical en el contexto del lenguaje audiovisual”, en: J. A. Sánchez López y F. García Gómez (coords.): Historia, estética e iconografía del videoclip musical, Málaga, Servicio de Publicaciones de la Universidad de Málaga, 2009, pp. 19-42.

32 Tesis, por ejemplo, de Fredric Jameson sobre el videoarte que aplicamos al videoclip por la filiación existente entre ellos (Jameson, F., "El surrealismo sin el inconsciente", en: Teoría de la postmodernidad, Madrid, Trotta, 1996, pp. 97-125). 
lenguaje propiamente artístico, al cine en el que hunde sus raíces, sea mínima, por no decir ninguna. Esta circunstancia explicaría que renombrados cineastas como Martin Scorsese, Brian de Palma o Tim Burton hayan hecho incursiones, de lo más brillantes además, en este ámbito creativo $^{33}$, al igual que hiciera Hitchcock con la teleserie y, tras él, otros muchos directores como Steven Spielberg, Francis Ford Coppola o David Lynch, acrecentando así la nómina de autores y productos midcult. Tan fina y tenue se ha vuelto en este sentido la línea de separación entre el videoclip y el arte que el traspaso de autores ha tenido lugar también en el otro sentido, por lo que realizadores de videos musicales como Michel Gondry, David Fincher o Chris Cunningham han acabado dirigiendo asimismo películas, muchas de las cuales además son consideradas hoy por hoy de culto.

Una situación parecida encontramos en el spot comercial, hijo igualmente del cine a través del cortometraje y exponente también de la midcult; pero no el anuncio convencional, el elaborado conforme a una lógica de adhesión acrítica y conformista, para nosotros sin especial interés, sino el de naturaleza narrativa o microrrelato, mucho más persuasivo, capaz de contar una historia completa en apenas treinta segundos; a veces, incluso en menos $^{34}$. Ello nos da una primera clave o peculiaridad estructural, pues aunque rigiéndose por los principios discursivos del cortometraje, donde la reducción temporal, junto a la de los personajes y localizaciones, es ya un imperativo, el anuncio extrema esa reducción al utilizar el mínimo de elementos para alcanzar, eso sí, la máxima efectividad narrativa. Ello se traduce, a efectos prácticos, en una historia esbozada a grandes rasgos, aunque lo suficientemente consistente como para despertar la curiosidad del espectador; máxime teniendo en cuenta que su construcción a partir también de un sorpresivo, irónico y/o ambiguo desenlace, donde a menudo queda en el aire el sentido último, lo invita a rellenar ese hueco, a implicarse, a fin de darle el cierre que le falta. Y no termina aquí esa participación, porque en el spot se radicaliza algo que empezó a despuntar en las teleseries de Hitchcock y a lo que sacaría partido después el videoclip: la apelación al conocimiento de la cultura de masas del destinatario. En sus teleseries, Hitchcock recurrió, efectivamente, a ese conocimiento, como nunca antes se había hecho, centrado en su caso en sus propias películas, con las que solía establecer conexiones visuales, bien sirviéndose de los mismos actores para ambos productos culturales, bien recreando escenas similares, hasta planteando argumentos parecidos. La empatía generada con el espectador mediante este tipo de acciones iría en aumento y volviéndose cada vez más sofisticada al ir incrementando la cultura de masas su número de productos; así, por ejemplo, en el video musical, a las lecturas, homenajes y parodias cinematográficas, es decir, a las citas cultas, que han sido muchas, se sumarían otras menos cultivadas como las inspiradas en el mundo del cómic o en la misma televisión.

33 Fenómeno del que daban cuenta ya en los años noventa David Bordwell y Kristin Thompson (El arte cinematográfico, Barcelona, Paidós, 2010, p. 36).

34 Otras veces, sin embargo, en más: cuando su distribución se produce, por ejemplo, a través de internet, donde es posible extenderse en el tiempo a voluntad (Selva, D., "Nuevos fenómenos en el entorno on line. La difusión del videoclip a través de Internet", Revista Telos, n 90, 2012. En Internet: http://telos.fundaciontelefonica.com/ seccion=1268\&idioma=es_ES\&id=2012020211040001\&activo=6.do [consulta: 13 -III-2015]). 
Es fácil imaginarse cómo resulta entonces esa sintonía con el público en el spot narrativo, uno de los últimos hallazgos de la cultura de masas, donde esa complicidad, repleta de intertextos y resignificaciones, está orientada a divertir al espectador en tanto en cuanto reconoce el texto y significado de origen, el llamado hipotexto, y se alegra de poder activarlos en su memoria, así como de apreciar la diferencia con el hipertexto donde se inserta ${ }^{35}$. De nuevo, pues, el reciclaje de imágenes y sonidos, lejos de echar a perder la grandeza de aquellas obras de donde están tomados, de arruinar la alta cultura, lo que hace es elevar el nivel cultural del anuncio, dejando a la vista de todos así que la publicidad excede hoy, con mucho, el propio terreno publicitario: no se conforma con incitar sin más a la compra del producto como antaño, sino que, con una factura mucho más cuidada y un propósito más delicado, o simplemente acercándose al arte, apela al bagaje audiovisual del receptor y, cuando carece de él, le invita a ampliarlo para llegar a entender lo que se le sirve por delante. Dicho de otro modo, que el spot narrativo, además de estimular la actividad sensible y emotiva con la diversión que procura y su incitación, la mayoría de veces, a la risa, pone en funcionamiento la mente, permite recordar, establecer comparaciones, deducir, sacar conclusiones $\mathrm{y}$, cuando no, ampliar conocimientos; pone a punto, en definitiva, el intelecto, tal y como se ha venido exigiendo tradicionalmente para catalogar algo de artístico y darle valor. Pero nada parece bastante para situar a este nuevo producto midcult donde le corresponde, que es en el dominio artístico, sin duda porque pesando todavía demasiado los prejuicios tipo MacDonald hacia los productos "de abajo", nada procedente de ese estrato inferior puede tenerse por "bueno" ni, consiguientemente, por arte.

Entendiendo que este tipo de objeciones están fuera de lugar en nuestro tiempo, numerosos cineastas se han aventurado en este nuevo ámbito creativo y han puesto de manifiesto así que hay que tomarlo más en serio de lo que habitualmente se hace y, lo que es más importante, han demostrado que dirigir anuncios ni los rebaja, ni les quita el calificativo de autores, ni los desposee de su aureola ${ }^{36}$; y eso que se trata de un terreno propicio para ello, porque en publicidad, a diferencia de lo que ocurre en el cine, la teleserie, incluso el videoclip, es difícil conocer la identidad del creador, de ese supuesto ser excepcional capaz de hacer cosas que nadie más puede hacer, al no ser portador de las típicas líneas de crédito -al principio o al final-y hacer suyo, en última instancia, el anonimato. Aún así, realizadores como el mencionado Scorsese, Ridley Scott, Baz Lurhmann o Guy Ritchie han transitado por este territorio menos noble -pero increíblemente rentable- que les ha permitido, en lo concerniente a lo de arriba, avanzar en la investigación fílmica y redundar en una mejora, si cabe, de sus productos de máxima calidad y, en lo de abajo, instruir al público en unas estrategias narrativas cada vez más esmeradas y familiarizarlo así con el lenguaje audiovisual de la excelencia. Como era de esperar, el fenómeno ha acontecido también a la inversa, de manera que muchos creativos publicitarios, que suelen ser al mismo tiempo realizadores de videoclips -los nombres se repiten, de hecho, en uno y otro caso-, han acabado dando el salto al sector cinematográfico y, sin embargo, sus películas no han sido "peores" ni han devaluado en algún sentido el cine.

35 Terminología de G. Genette en Palimpsestos: la literatura en segundo grado, Madrid, Taurus, 1989.

36 Meier A.-M., "Cine y spot publicitario", El ojo que piensa. Revista de cine iberoamericana, no 4, 2011. En internet: http://www.elojoquepiensa.net/elojoquepiensa/index.php/numeros_anteriores/114 (consulta: 4-III-2015). 


\section{Conclusión}

Aunque desde la estética y la teoría del arte se han venido compartimentado y estratificando las artes desde siempre, esa práctica parece haberse quedado obsoleta en nuestros días. El engrosamiento de la clase media, una clase educada y con amplia formación cultural, producto de la sociedad del bienestar generalizada en occidente desde los años sesenta, ha favorecido la constitución de un arte y una cultura específica para ella, la midcult, a partir de la convergencia de la cultura "respetable" y la "burda" del populacho. Así, las formas características de la verdadera cultura se han difundido in extenso, pero sin conducirse por ello al desastre. Por tanto, lo de arriba no ha acabado deteriorándose y hundiéndose indefectiblemente en lo de abajo, según el vaticinio de MacDonald para el futuro. Ha sido, por el contrario, lo de abajo lo que en general ha ido escalando puestos y la cultura, lo que a la postre ha sacado auténtico provecho, pues esa confluencia se ha traducido en expresiones artísticas tan novedosas como trabajadas -ahí está el ejemplo del cine y sus derivados para corroborarlo-, con las que el público ha ido creciendo también, desarrollándose y alcanzando, por decirlo de algún modo, cierta mayoría de edad receptiva -siempre que ha estado dispuesto a ello, claro, y ha sido ése el objetivo-. A la luz de esta realidad, la distinción entre alta y baja cultura se habría vuelto hoy inapropiada para distinguir, como en el pasado, entre artes mayores y menores en tanto ámbitos perfectamente definidos y acotados, a la vez que opuestos y enfrentados.

Pese a todo, es un hecho indiscutible que el afán jerarquizante sigue operando institucional y terminológicamente en el presente, si bien de manera distinta, ya no en sentido longitudinal como antaño, sino transversal a fin de calificar las obras de más o menos artísticas en función de su mayor o menor calidad, es decir, en función de si su propósito es meramente comercial -ahondando así en su aspecto puramente masivo- o si hay en ellas algo más -deseo de perdurabilidad o cuestionamiento del sistema social, por ejemplo-. El panorama ha cambiado, pues, y mucho: esa transversalidad indicaría que a priori todas las prácticas artísticas se hallan por fin al mismo nivel; todas serían en principio igual de dignas -un cómic ya no sería menos que una pintura-, aunque después tuvieran diferente valor -un cómic sería más o menos artístico que otro cómic, al igual que una pintura lo sería también respecto a otra pintura-. Lejos de rivalizar entonces entre ellas, lo harían dentro de ellas, redundando así en un progreso y enriquecimiento de sí mismas, del arte y la cultura en sentido amplio y universal.

\section{Referencias}

Belting, Hans (2009): Imagen y culto: una historia de la imagen anterior a la edad del arte, Akal, Madrid.

Bordwell, David (1995): El significado del filme, Paidós, Barcelona.

Bordwell, David y Thompson, Kristin (2010): El arte cinematográfico, Paidós, Barcelona. Burch, Noël (1987): El tragaluz del infinito, Cátedra, Madrid.

Busquet, Jordi (2008): Lo sublime y lo vulgar. La "cultura de masas" o la pervivencia de un mito, Editorial UOC, Barcelona.

Carroll, Noël (2002): Una filosofía del arte de masas, Antonio Machado Libros, Madrid. 
Castro, Sixto J. (2002): “Reivindicación estética del arte popular, Revista de Filosofía, vol. 27, nº 2, pp. 431-451.

Castro de Paz, José Luis (1999): El surgimiento del telefilme. Los años cincuenta y la crisis de Hollywood: Alfred Hitchcock y la televisión, Paidós, Barcelona.

Crown, Thomas (2002): El arte moderno en la cultura de lo cotidiano, Akal, Madrid.

Danto, Arthur (1999): Después del fin del arte. El arte contemporáneo y el linde de la historia, Barcelona, Paidós.

De Felipe, Fernando (2006): "La sombra de una de(u)da: publicitarios y cineastas", Trípodos, $\mathrm{n}^{\circ} 18$, pp. 95-108.

Eco, Umberto (2009): Apocalípticos e integrados, Lumen, Barcelona.

Fernández, Rosa (2008): "La estética invisible del arte popular", Suplementos de Contrastes. Revista Internacional de Filosofía, $\mathrm{n}^{\circ} 13$, pp. 41-54.

Fontán del Junco, Manuel et al. (2012): La vanguardia aplicada (1890-1950), catálogo de exposición, Fundación Juan March, Madrid.

Genette, Gerard (1989): Palimpsestos: la literatura en segundo grado, Taurus, Madrid.

Greenberg, Clement (2002): "Vanguardia y kitsch", en Arte y cultura, Paidós, Barcelona, pp. 15-46.

Infante del Rosal, Fernando (2015): "Las tres estéticas y el límite", Estudios Filosóficos, vol. $64, \mathrm{n}^{\circ} 185$, pp. $35-48$.

Jameson, Fredric (1996): "El surrealismo sin el inconsciente", en Teoría de la postmodernidad, Trotta, Madrid, pp. 97-125.

Macdonald, Dwight (2011): "Masscult and Midcult", en Masscult and Midcult. Essays against the American grain, The New York Review of Books, Nueva York, pp. 3-71.

Meier, Anne Marie (2011): "Cine y spot publicitario", El ojo que piensa. Revista de cine iberoamericana, $\mathrm{n}^{\mathrm{o}}$ 4. En internet: http://www.elojoquepiensa.net/elojoquepiensa/index. php/numeros_anteriores/114 (consulta: 4-III-2015).

Pardo, José Luis (2007): Esto no es música. Introducción al malestar en la cultura de masas, Círculo de Lectores/Galaxia Gutenberg, Barcelona.

Rancière, Jacques (2009): El reparto de lo sensible. Estética y política, LOM Ediciones, Chile.

Schaeffer, Jean Marie (2005): Adiós a la estética, Antonio Machado Libros, Madrid.

Sedeño Valdellós, Ana Ma (2009): "El videoclip musical en el contexto del lenguaje audiovisual”, en: J. A. Sánchez López y F. García Gómez (coords.): Historia, estética e iconografía del videoclip musical, Servicio de Publicaciones de la Universidad de Málaga, Málaga, pp. 19-42.

Selva, David (2012): "Nuevos fenómenos en el entorno on line. La difusión del videoclip a través de Internet", Revista Telos, $\mathrm{n}^{\circ}$ 90. En Internet: http://telos.fundaciontelefonica. com/seccion=1268\&idioma=es_ES\&id=2012020211040001\&activo=6.do [consulta: 13-III-2015].

Shiner, Larry (2004): La invención del arte. Una historia cultural, Paidós, Barcelona.

Thompson, Kristin (1997): “De primitivo a clásico”, en: D. Bordwell, J. Staiger y K. Thompson: El cine clásico de Hollywood. Estilo cinematográfico y modo de producción hasta 1960, Paidós, Barcelona, pp. 171-190.

Truffaut, François (2003): El cine según Hitchcock, Alianza, Madrid. 
